\section{Prédisposition héréditaire au cancer du sein (1)}

\section{Génétique}

$>$ L'oncogénétique a pour objectif principal de caractériser une sous-population à haut risque de développement de cancers à un âge précoce afin de préconiser les recommandations pour un parcours optimisé de suivi et de soins. La consultation d'oncogénétique contribue à évaluer un risque individuel à partir d'une histoire familiale. Par une approche familiale de génétique formelle, il s'agit de repérer les familles avec une forte agrégation de cancers, éventuellement évocatrice d'un syndrome de prédisposition héréditaire. Cette démarche peut conduire à la proposition d'un test génétique constitutionnel à la recherche de mutations causales. Jusqu'à une période récente, la recherche de mutation constitutionnelle sur les gènes BRCA a abouti à l'identification d'une mutation délétère chez moins de $10 \%$ des cas-index analysés. II est donc important d'évaluer l'impact de nouveaux gènes dans le panorama actuel de la prédisposition héréditaire au cancer du sein et de l'ovaire. «

Les objectifs de l'oncogénétique sont de caractériser et de prendre en charge la surveillance et le suivi d'une sous-population à haut risque de développement de cancers à un âge précoce pour laquelle les dispositions du dépistage organisé en population générale sont inadaptées. L'oncogénétique, ou génétique constitutionnelle des cancers, concerne la prise en considération et l'analyse des altérations génétiques héritées, c'est-à-dire "germinales » ou «constitutionnelles», qui peuvent être mises en évidence dans les cellules d'un individu. Toutes les cellules d'un même organisme contiennent le même patrimoine génétique qui résulte de la fusion inaugurale du gamète paternel et de l'ovocyte maternel, au moment de la fécondation. La génétique moléculaire des cancers, ou génétique tumorale ${ }^{1}$, concerne, elle, les altérations

La partie 2 (Prédisposition héréditaire au cancer du sein : risques et prise en charge) sera publiée dans un prochain numéro.

Vignette (Photo @ Inserm - Henri Rochefort).

${ }^{1}$ Le terme «tumoral » est plus approprié que celui de « somatique » qui est impropre puisque l'ADN des cellules somatiques est l'ADN germinal, constitutionnel, unique pour un individu donné.
Odile Cohen-Haguenauer ${ }^{1,2}$

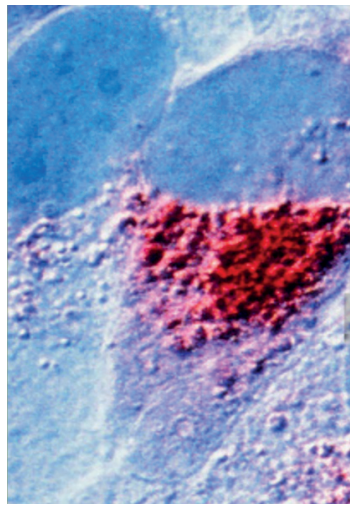

${ }^{1}$ Unité d’Oncogénétique, Service d'oncologie médicale, pôle HI-3RO et faculté de Médecine, université Paris 7 Denis Diderot, USPC

${ }^{2}$ Hôpital Saint-Louis, l, avenue Claude Vellefaux, 75475 Paris Cedex 10, France.

odile.cohen-haguenauer@aphp.fr

génétiques acquises retrouvées et analysées au niveau des cellules cancéreuses. Ces dernières ne seront donc pas envisagées ici.

La consultation d'oncogénétique contribue à mesurer un risque individuel à partir d'une histoire familiale pour en tirer les recommandations sur un parcours optimisé de suivi et de soins. Le domaine, sensible et complexe, est régi par les lois de bioéthique (voir Encadré) : la confidentialité des données génétiques individuelles doit être strictement respectée; dans une famille, une information ne peut donc circuler que par l'intermédiaire et selon la volonté des personnes qui l'ont reçue de leur médecin qui ne doit prendre aucune initiative pour solliciter directement les apparentés, à l'exception de la situation rare où il est saisi par un sujet qui est porteur d'une mutation (selon l'obligation légale de transmettre à sa place et à sa demande l'information anonyme à ses apparentés ${ }^{2}$ ).

L'oncogénétique comporte une dimension familiale: l'estimation du risque pathologique de cancer et la prise en charge médicale optimisée de sujets à très haut risque de développer des cancers. C'est à travers une approche familiale dite de génétique formelle - c'est à dire le tracé d’un arbre généalogique si possible sur 4-5 générations - que sont repérées les familles avec une forte agrégation de cancers, souvent sur plusieurs générations, et d'en dégager des traits évocateurs d'un syndrome de prédisposition au cancer. Elle conduit à la proposition d'un test génétique, à la recherche de mutations familiales causales. La consultation d'oncogénétique contribue ainsi à mesurer un risque individuel à partir d'une histoire familiale pour en tirer les recommandations sur un parcours optimisé de suivi et de soins.

${ }^{2}$ Décret n 2013-527 du 20 juin 2013. 


\section{La législation française}

- Les dispositions légales concernant l'information préalable à la signature du consentement éclairé indispensable à la réalisation d'un test génétique constitutionnel sont décrites dans l'article R1131-4 du Code de Santé Publique, la loi du 07/07/2011 relative à la bioéthique et le décret $n^{\circ} 2013-357$ du 22/06/2013.

- En cas d'anomalie génétique identifiée permettant des mesures de prévention ou de soins, la personne testée la première dite «cas index », est dans l'obligation d'informer de la disponibilité d'un test prédictif, directement ou par l'intermédiaire du médecin, ceux des membres de sa famille potentiellement concernés. En cas de refus, la responsabilité pénale du cas index pourra être engagée (décret $\mathrm{N}^{\circ} 2013-357 \mathrm{du} 22 / 06 / 13$ ).

- Les données concernant les patients soumis au test génétique peuvent faire l'objet d'un traitement informatique et sont protégées par les dispositions de la loi «informatique et libertés» (loi $n^{\circ} 78-17$ de janvier 1978, modifiée). Le patient dispose à tout moment d'un droit d'accès et de rectification.

- Le médecin prescripteur doit conserver le consentement écrit, les doubles de la prescription et de l'attestation, et les comptes rendus d'analyses de biologie médicale commentés et signés (Art. R. 1131-20). - Le laboratoire agréé réalisant les examens doit :

- Disposer de la prescription et de l'attestation du prescripteur (Art. R. 1131-20).

- Adresser les comptes rendus d'analyse commentés et signés par un praticien agréé conformément à l'Art. R.1131-6 exclusivement au médecin prescripteur qui communiquera les résultats de l'examen des caractéristiques à la personne concernée dans le cadre d'une consultation individuelle (Art. R.1131-19).

Le développement de l'oncogénétique constitue une priorité du Plan cancer 3. La Haute autorité de santé (HAS) et l'Institut national du cancer (INCa) ont formulé des recommandations de prise en charge des sujets à haut risque de cancer $^{3,4}$; dans d'autres pays et, notamment les États-Unis, des dispositions du même ordre sont entreprises et les recommandations régulièrement actualisées ${ }^{5}$ dans ce domaine rapidement évolutif. Les programmes personnalisés de suivi (PPS), définis lors des réunions de concertations pluridisciplinaires (RCP), sont conditionnés par la consultation préalable d'oncogénétique et l'avis émis par un oncogénéticien.

La prise en charge organisée avec le soutien de l'INCa depuis le début des années 2000 (dispositif national d'oncogénétique ${ }^{6}$ ), a abouti à la constitution de réseaux et à la mise en place de bases de données. II

\footnotetext{
${ }^{3}$ Haute autorité de santé (HAS) http://www.has-sante.fr/portail/jcms/c_l741170/fr/depistage-ducancer-du-sein-en-france-identification-des-femmes-a-haut-risque-et-modalites-de-depistage, mai 2014.

${ }^{4}$ Institut national du cancer (INCa) : http://www.e-cancer.fr/Expertises-et-publications/Cataloguedes-publications/Femmes-porteuses-d-une-mutation-de-BRCAl-ou-BRCA2-Detection-precoce-ducancer-du-sein-et-des-annexes-et-strategies-de-reduction-du-risque, mai 2017

${ }^{5}$ National comprehensive cancer network (NCCN). NCCN clinical practice guidelines in oncology - genetic/ familial high-risk assessment: breast and ovarian : https:/ / www .nccn .org/professionals/ physician_gls/f_guidelines .asp

${ }^{6}$ Un rapport annuel comprenant des indicateurs qualitatifs et quantitatifs doit être restitué par chaque structure faisant l'objet d'un soutien financier.
}

existe actuellement au plan national 17 réseaux, dont le SAR (seins à risque) AP-HP, centré sur les cancers du sein et des ovaires, qui doivent permettre d'offrir un maillage national et un suivi homogène pour tous les sujets repérés comme étant à risque génétique de cancer.

\section{Pourquoi penser au risque héréditaire de cancer du sein?}

\section{La prédisposition héréditaire au cancer}

Environ 5 à $10 \%$ des cancers du sein apparaissent dans un contexte familial. Dans la majorité des cas, ces cancers surviennent avant l'âge où est instauré un dépistage systématique dans la population générale (entre 50 et 74 ans). En effet, dans la tranche d'âge 25-40 ans, l'influence de l'hérédité dépasse un tiers des cas. La consultation d'oncogénétique et de dépistage précoce des cancers permet de reconnaître un contexte de prédisposition familiale et de mettre en place une stratégie de surveillance ciblée sur cette population de sujets très jeunes.

Les altérations génétiques en question sont héréditaires et peuvent être transmises de génération en génération. Dans la plupart des cas, il s'agit d'une transmission autosomique dominante : un parent porteur a un risque sur deux de transmettre la prédisposition à chacun de ses enfants, soit $50 \%$ (il est important pour les personnes et familles concernées, de savoir que cette transmission n'est donc pas inexorable). Il peut s'agir d'une transmission par le père ou par la mère, avec la même probabilité, indépendante du genre du parent chez qui la mutation prend son origine. En moyenne, dans chaque fratrie, un enfant sur deux en est porteur. Cependant et par hasard, dans certaines fratries, tous les enfants sont porteurs et dans d'autres aucun ne l'est. De plus, dans la plupart des syndromes d'hérédité au cancer, la pénétrance du gène muté est incomplète, le développement d'un cancer n'est donc pas inéluctable [1].

\section{Les gènes BRCA1 et BRCA2}

Les gènes $B R C A$ (breast cancer) 1 et 2 , comme environ 30000 autres gènes, font partie de notre patrimoine génétique. BRCAl fut le premier gène identifié comme gène de susceptibilité au cancer du sein. Localisé en 1990 sur le chromosome 17, en 17q12-2, par analyse de liaison dans une trentaine de familles à risque [2], il a été caractérisé en 1994 [3] : il compte 83 kilobases (kb) dont 5,7 kb de séquences codantes réparties sur 22 exons. BRCA2, localisé en 1994 sur le chromosome 13 dans la région q12-13(22), a été cloné en 1995. II 
est constitué de 26 exons, avec des séquences codantes représentant $10,2 \mathrm{~kb}$ sur un total de $86 \mathrm{~kb}$ [4]. Les deux gènes contribuent de façon complémentaire à un mécanisme commun de protection du génome. Ils codent des protéines essentiellement impliquées dans la réparation des cassures double brin de I'ADN par recombinaison homologue [5-10]. Dans les modèles murins [11], l'inactivation du gène Brcal à l'état homozygote aboutit à l'interruption de l'embryogenèse au jour 7,5. Cette létalité est liée à l'inhibition de la prolifération nécessaire au développement des différentes couches embryonnaires, par arrêt de réplication de I'ADN.

La protéine BRCAl, d'environ 220 kDa formée de 1863 acides aminés, est constituée [8, 10] (1) d'un domaine RING (really interesting new gene) en $\mathrm{N}$-terminal, qui possède une activité $\varepsilon 3$ ubiquitine ligase qui catalyse l'ubiquitination des protéines. Cette activité est favorisée par l'association avec le domaine RING de la protéine BARDI (BRCAl-associated RING domain protein 1), formant un hétérodimère BRCAl-BARDl; (2) de deux domaines BRCT (BRCAl C-terminal) en C-terminal, également retrouvés dans de nombreuses protéines impliquées dans la réparation de l'ADN et le cycle cellulaire. Ils permettent la liaison de BRCAl aux protéines phosphorylées Abraxas (membre de la famille des protéines FAM175), BRIPl (BRCAl interacting protein C-terminal helicase 1 ) et CtIP (CtBp-interacting protein). Les complexes ainsi formés ont diverses fonctions dans la réponse aux altérations de I'ADN : recrutement aux sites de cassure de l'ADN, résection de la cassure, réparation de I'ADN, régulation des points de contrôle du cycle cellulaire; et (3) d'un domaine en hélice, qui intervient dans le complexe BRCA1-BRCA2-PALB2 (partner and localizer of BRCA2) impliqué dans la réparation des cassures de l'ADN, par recombinaison homologue, seul mécanisme de réparation de l'ADN capable d'une réparation fidèle et de maintenir l'intégrité du génome. La recombinaison homologue implique la détection des altérations parles protéines «senseurs » ATM (Ataxia telangiectasia mutated) et ATR (Ataxia telangiectasia and RAD3-related), la médiation des signaux par CHEK2 (checkpoint kinase 2) et BRCAl, et l'initiation de la réparation par les effecteurs BRCA2 et RAD51. Deux facilitateurs interviennent également dans ce processus: PALB2 et BRIP1. Chacun de ces acteurs entraîne une forme de prédisposition au cancer du sein lorsqu'il est muté de façon constitutionnelle.

La protéine BRCA2, de 384 kDa formée de 3418 acides aminés, sans homologie avec la protéine BRCAl, comprend $[10,12,13]$ : (1) un domaine de liaison à l'ADN, constitué d'un domaine hélicoïdal $(H)$, de trois domaines de liaison aux oligonucléotides $(O B)$, et d'un domaine en tour (T), qui permet sa liaison à I'ADN simple-brin ; (2) deux domaines NLS (signaux de localisation nucléaire) et un site de phosphorylation par des CDK (kinases cyclines-dépendantes) en C-terminal, auxquels se lie RAD51. Huit répétitions BRC, dans sa partie centrale, permettent également son interaction avec RAD51. Une molécule de BRCA2 peut lier six molécules RAD51 au niveau de son domaine central et de son domaine C-terminal. L'interaction importante de BRCA2 avec la protéine PALB2 sera développée dans la section relative à ce gène (voir plus loin).

\section{Perte d'hétérozygotie}

Les gènes BRCAl et BRCA2 du fait de leurs fonctions mixtes répondent à la fois à la définition de gènes « gardiens du génome » (ou caretakers) - intervenant dans le maintien de son intégrité par la réparation des lésions double brin de l'ADN -, et de gènes suppresseurs de tumeurs $[8,9,14,15]$. La majorité des mutations constitutionnelles qui les touchent sont de type «perte de fonction », de transmission autosomique dominante. La théorie des deux évènements de Knudson [16], initialement proposée en 1971 en utilisant le modèle du rétinoblastome, explique le processus de tumorigenèse, par l'inactivation successive des deux allèles d'un gène suppresseur de tumeurs dans une même cellule. Il suppose l'existence d'une première mutation constitutionnelle, héritée ou de novo, sur l'un des allèles du gène, puis la survenue d'une seconde mutation somatique sur l'autre allèle. Ces deux mutations successives entraînent une inactivation du gène avec, pour conséquence, l'initiation du processus de cancérogenèse. Ce modèle s'applique au syndrome de prédisposition héréditaire au cancer du sein chez les femmes porteuses d'une mutation constitutionnelle de BRCAl ou de BRCA2 (Figure 1).

\section{Le syndrome sein/ovaire}

Chez approximativement une personne sur 500 , l'un des gènes $B R C A 1$ ou $B R C A 2$ est altéré et à l'origine, chez les femmes, d'une prédisposition génétique majeure aux cancers du sein et de l'ovaire. Le risque tumoral mammaire, cumulé au cours de la vie, est important ; il s'agit souvent de cancers de survenue précoce chez l'adulte jeune. En cas de mutation de BRCAl, à l'âge de 70 ans, les risques cumulés de cancer du sein et de l'ovaire sont respectivement, de l'ordre de $65-80 \%$ et de $40 \%$; pour $B R C A 2$, ils sont d'environ $45-60 \%$ et $10-40 \%$ [17-19] (Figure 2B). Le risque de cancer ovarien chez les femmes porteuses d'une mutation BRCA2 varie en fonction de la localisation de la mutation sur le gène : il est majeur dans la région centrogénique (OCCR pour ovarian cancer cluster region) [20]. Récemment, Kuchenbaecker et al., ont évalué des scores de risque polygéniques afin d'affiner la prédiction des risques de cancer du sein et/ou de l'ovaire chez les porteurs de mutations des gènes $B R C A$ [21]. S'agissant de BRCAl, on observe un rajeunissement de l'âge au diagnostic de génération en génération et le risque de développer un cancer du sein controlatéral, après un premier cancer du sein, augmente de 2 à $4 \%$ par an ; il serait un peu plus faible dans le cas d'une mutation du gène BRCA2 [22]. Si le risque d'atteintes ovarienne ou tubaire (aussi appelées annexes) est moins élevé que le risque mammaire en 


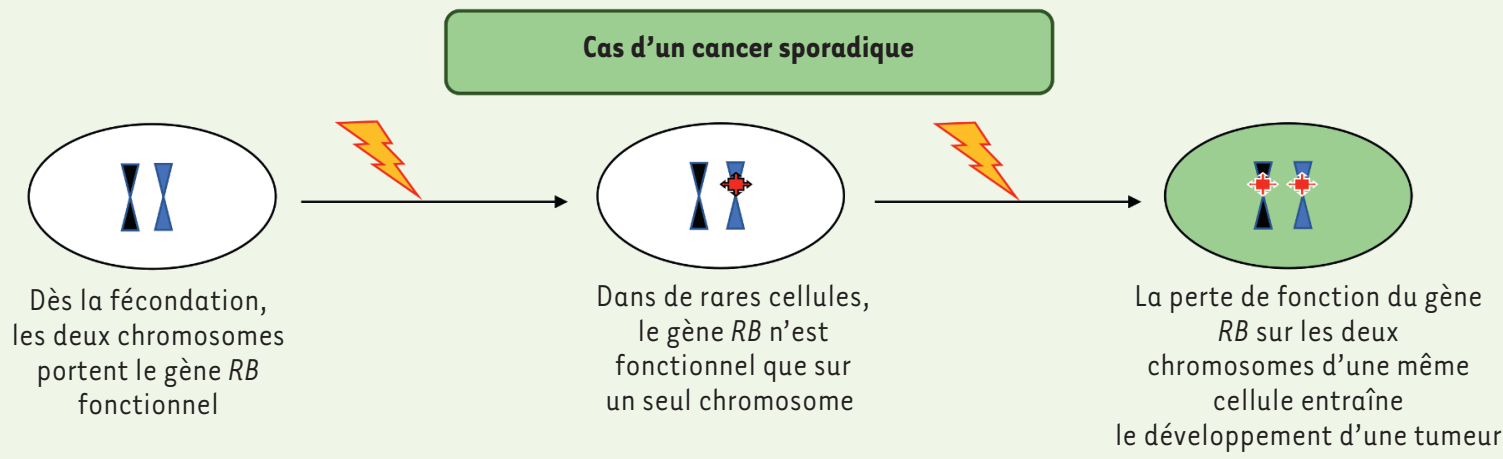

Cas d'un cancer héréditaire

L'enfant hérite d'un chromosome portant le gène $R B$ défectueux de l'un de ses parents

Événement mutationnel

Gène non fonctionne

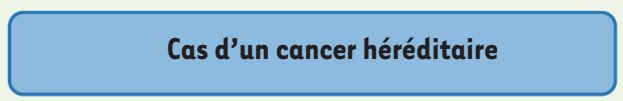

e développement d'une tumeur

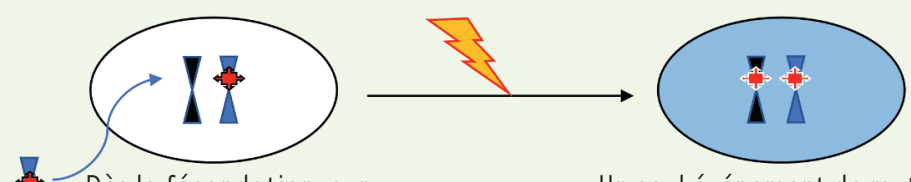

Dès la fécondation, sur

l'ensemble des cellules, le gène $R B$ n'est

fonctionnel que sur un seul chromosome
Un seul événement de mutation conduit à la perte de fonction du gène $R B$ sur les deux chromosomes et au développement d'une tumeur

Figure 1. Hypothèse de Knudson. RB : gène suppresseur de tumeurs associé au rétinoblastome.

valeur absolue, il est beaucoup plus fréquent, de manière relative, que dans la population générale où le risque est inférieur à une femme sur 100. S'agissant de BRCA2, il existe un risque supplémentaire modéré (environ $5 \%$ ) d'association avec un cancer du pancréas [23] ou un mélanome [24], quel que soit le sexe. Si une surveillance clinique annuelle est recommandée, les explorations complémentaires sont indiquées, en particulier en cas d'antécédent familial de cancer du pancréas et en cas de doute, mais pas de façon systématique. Chez les hommes, il existe pour les mutations touchant BRCA2 un sur-risque modéré d'atteinte mammaire [25] et de la prostate ( $5 \%$ ). Ces cancers de la prostate semblent plus agressifs que dans la population générale et appellent une surveillance spécifique, dès l'âge de 45 ans [26-28]. S'agissant de $B R C A 1$, on relève une discrète augmentation du risque relatif de mélanome, de cancer du côlon et du rein qui surviennent plus volontiers après 60 ans pour ces deux dernières localisations. Chez l'homme porteur d'une mutation de BRCAl, le risque de cancer du sein ou de la prostate reste anecdotique comparé à celui associé aux mutations de BRCA2 [29, 30].

\section{Caractéristiques des tumeurs BRCA}

Les femmes porteuses d'une mutation du gène BRCAl développent des cancers du sein à un âge plus précoce que dans la population générale. Dans l'étude de Eerola et al. [31], l'âge moyen des patientes au diagnostic est de 44 ans, significativement plus jeune que dans la population générale, où il est de 56 ans, et plus de $60 \%$ des cancers du sein surviennent avant 50 ans chez ces femmes. Le risque de cancer du sein augmente fortement entre 30 et 50 ans. II s'équilibre ensuite (Figure 2). Les tumeurs de ces patientes sont majoritairement des carcinomes canalaires infiltrants, de grade élevé ( $85 \%$ de grade $\mathrm{II}$ ), avec un important infiltrat lymphocytaire et des foyers de nécrose [32]. Plus de $80 \%$ des tumeurs ayant pour origine des mutations de $B R C A l$ sont de phénotype triple-négatif (n'exprimant ni récepteurs des œstrogènes ni récepteur de la progestérone et ne présentant pas d'amplification du récepteur Her2-neu [ou ErbB-2, human epidermal growth factor receptor 2]) $[33,34]$. Ces tumeurs ne relèvent donc pas d'une hormonothérapie. On observe également une plus forte incidence de mutations du gène suppresseur de tumeurs TP53 dans ces tumeurs (50-77\%) que dans les tumeurs sporadiques (20\%) [31] avec un index de prolifération (révélé par la détection de l'antigène nucléaire Ki67) plus élevé et une surexpression des cyclines $\varepsilon$ et $A$, qui activent la progression du cycle cellulaire. Les protéines p16, p27 et p21 qui inhibent le complexe cyclineCDK et les cytokératines de haut poids moléculaire (CK 5,14 et 17) y sont sous-exprimées. Ces caractéristiques sont similaires à celles observées dans les tumeurs du sein basal-like non héréditaires. Si les tumeurs BRCAl sont plus agressives, elles apparaissent, en revanche, plus sensibles aux agents cytotoxiques, ce qui améliore significativement leur pronostic $[35,36]$. 
A

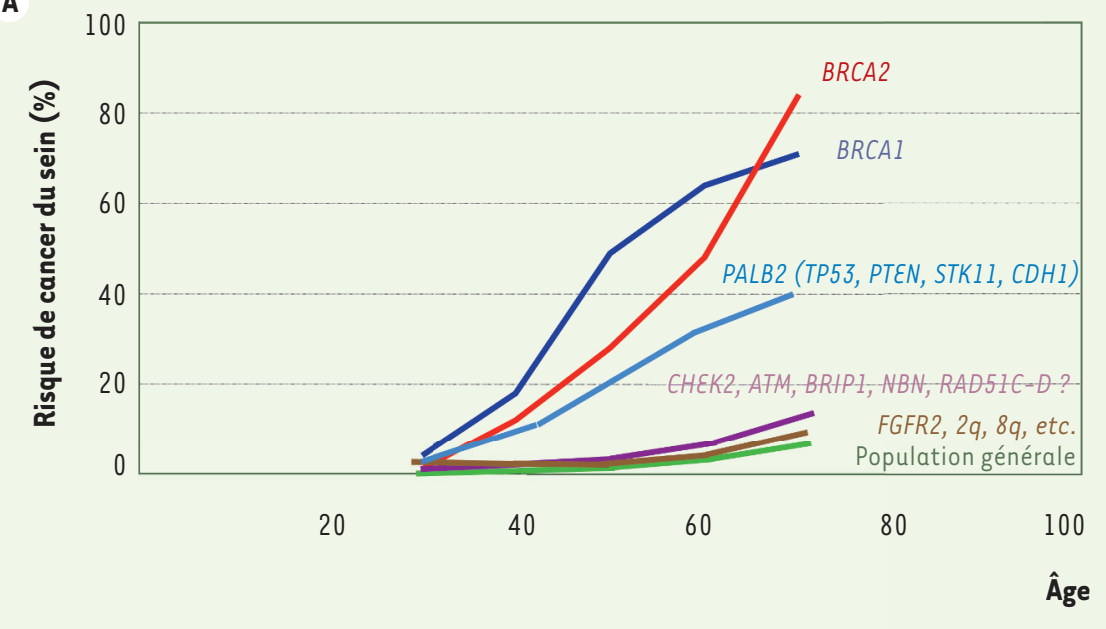

B

\begin{tabular}{|c|c|c|}
\hline & BRCA1 & BRCA2 \\
\hline $\begin{array}{c}\text { Sein } \\
{[1]}\end{array}$ & $65 \%(\mathrm{Cl}: 44-78 \%)$ & $45 \%(\mathrm{Cl}: 31-56 \%)$ \\
{$[3]$} & $57 \%(\mathrm{Cl}: 47-66 \%)$ & $49 \%(\mathrm{Cl}: 40-57 \%)$ \\
\hline $\begin{array}{c}\text { Ovaire } \\
{[1]}\end{array}$ & $39 \%(\mathrm{Cl}: 18-54 \%)$ & $11 \%(\mathrm{Cl}: 2,4-19 \%)$ \\
{$[3]$} & $40 \%(\mathrm{Cl}: 35-46 \%)$ & $18 \%(\mathrm{Cl}: 13-23 \%)$ \\
\hline
\end{tabular}

Les femmes porteuses d'une mutation du gène BRCA2 développent également des cancers du sein à un âge plus précoce que celles de la population générale. Dans l'étude de Eerola et al. [31], l'âge moyen de ces patientes au diagnostic est de 47 ans, significativement plus jeune que dans la population générale où il est de 56 ans. Le risque de survenue d'un cancer du sein augmente progressivement avec l'âge chez ces femmes et audelà de 80 ans, contrairement aux femmes dont le gène BRCAl est altéré (Figure 2). Les tumeurs des patientes présentant des mutations de BRCA2 sont hétérogènes, sans type histologique prédominant et ressemblent aux tumeurs du sein sporadiques. Elles expriment les récepteurs des œstrogènes et de la progestérone dans $60 \%$ des cas [37], ne surexprimant ni HER2/neu, ni les cytokératines basales CK 5/6 [38]. Elles sont cependant souvent de grade plus élevé [39]. Ces tumeurs sont beaucoup moins fréquemment de type triple-négatif ou mutées sur le gène TP53 [40] que celles présentant des mutations du gène BRCAl : elles sont donc classées dans le phénotype luminal, malgré leur haut grade histologique. Des études ont également montré une surexpression des protéines impliquées dans la carcinogenèse, comme la cycline Dl et/ou Myc dans ces tumeurs [41]. Du fait de la présence de récepteurs hormonaux, elles relèvent le plus souvent d'une hormonothérapie d'entretien. Dans une étude récente, Copson et al. [42] ont analysé le pronostic des cancers du sein de survenue précoce, avant 40 ans, chez des femmes porteuses de mutations des gènes $B R C A 1$ ou BRCA2. Si la survie était équivalente à celle des patientes non mutées, un avantage, s'agissant des tumeurs triple-négative, a été enregistré en faveur des personnes porteuses de mutations.
Figure 2. A. Risque de cancer du sein selon les gènes présentant une mutation et l'âge de la patiente. $B$. Les risques cumulés de cancer du sein et de l'ovaire jusqu'à 70 ans selon les mutations de BRCA1 ou BRCA2 sont indiqués $[1,3]$. Dans le cas du gène $B R C A 2$, le risque continue à augmenter après 70 ans. $\mathrm{Cl}$ : intervalle de confiance.

\section{Les autres gènes de prédisposition au cancer du sein et de l'ovaire}

\section{Les gènes de forte pénétrance et de fréquence allélique rare}

Les gènes dont les mutations sont rares, mais de forte pénétrance, confèrent un risque relatif de cancer du sein supérieur à 4 selon la définition proposée par Easton et al. [43] qui fait référence au niveau international.

\section{Le gène PALB2}

Le gène PALB2 est situé sur le chromosome 16. II constitue avec BRCA2 un médiateur de la recombinaison homologue, contribuant aux mécanismes de réparation de l'ADN et à la suppression des tumeurs $[44,45]$. Une mutation bi-allélique de PALB2 est à l'origine d'une anémie de Fanconi, à l'instar de ce qui a été observé pour une mutation bi-allélique de BRCA2 [7, 46].

La fréquence allélique globale, estimée sur une population de près de 100000 cas de cancers du sein, est de $1 \%$; elle varie cependant de 0,2 à $2,5 \%$ selon les cohortes étudiées. Les études estimant le risque de cancer du sein chez les femmes porteuses de mutations du gène PALB2 rapportent un risque très élevé, voisin de celui observé chez les femmes porteuses de mutations des gènes BRCA1 ou BRCA2 [47-61]. Cybulski et al. [62] ont récemment étudié les caractéristiques des tumeurs du sein et le pronostic des patientes porteuses d'une mutation du gène PALB2. En comparant 116 patientes mutées dans le gène $P A L B 2$ à 435 patientes mutées dans le gène $B R C A l$ et à 11978 patientes ne présentant pas de mutations, ils ont montré que les patientes mutées dans le gène PALB2 présentaient majoritairement des tumeurs du sein de phénotype triple-négatif, et que leur survie à 10 ans était significativement plus basse que celle des patientes mutées dans le gène BRCAl et des patientes contrôles. À noter que l'éventualité d'une prédisposition héréditaire au cancer du pancréas a aussi été évoquée [47, 63]. 
Le niveau de risque rapporté par ces études a été approuvé par le Groupe génétique et cancer d'Unicancer ${ }^{7}$ [64]. II est donc établi que le niveau de risque de cancer du sein chez les femmes porteuses d'une mutation du gène PALB2 est considéré comme «très élevé », selon la terminologie du référentiel de I'HAS de $2014^{3}$. L'analyse du gène PALB2 est systématiquement réalisée lorsque le contexte personnel ou familial est évocateur d'un syndrome dit HBOC (hereditary breast and ovarian cancer) chez les femmes cas-index (atteintes de cancer). Les tests génétiques chez les apparentés peuvent être mis en œuvre car le statut porteur/non porteur de la mutation est jugé suffisamment discriminant pour le risque de cancer pour identifier deux groupes de femmes justifiant de prises en charge différentes.

\section{Le gène PTEN}

Le gène PTEN (phosphatase and tensin homolog) est un gène suppresseur de tumeur localisé sur le chromosome 10, en 10q23.3 [65]. II code une phosphatase antagoniste de la PI3K (phosphatidylinositol-3-kinase). Un dysfonctionnement de PTEN empêche l'arrêt du cycle cellulaire et l'apoptose et conduit à une survie anormale des cellules [66]. La survenue d'un cancer du sein ne résume pas à elle seule la maladie qui correspond à un ensemble phénotypique complexe, associant des atteintes des tissus dérivés des trois lignées embryonnaires. Le syndrome de Cowden ${ }^{8}$ entre dans le cadre des prédispositions héréditaires au cancer d'ordre syndromique [67]. Son diagnostic clinique peut être difficile, nécessitant souvent un recours à des avis spécialisés et sa confirmation moléculaire par la mise en évidence d'une altération du gène PTEN. Une mutation germinale avec perte de fonction de PTEN peut conduire au syndrome de Cowden [68], mais aussi au syndrome pédiatrique de Bannayan-Riley-Ruvalcaba ${ }^{9}$.

Les patientes porteuses d'une mutation germinale du gène PTEN ont un risque augmenté de cancer du sein : $50 \%$ développent un cancer du sein au cours de leur vie, à un âge moyen de 40 ans, avec parfois des diagnostics très précoces d'histologie pathognomonique : carcinome canalaire entouré de collagène hyalinisé, cancers de la thyroïde, du rein, de l'endomètre voire colo-rectaux [69-71]. Selon l'expertise d'Unicancer, le niveau de risque de cancer du sein des femmes porteuses d'une mutation du gène PTEN est considéré comme « très élevé » et les tests génétiques chez les apparentés peuvent être mis en œuvre.

\section{Le gène TP53}

Une mutation constitutionnelle du gène TP53 constitue, dans sa forme classique, le syndrome de Li Fraumeni, à la présentation très polymorphe dont les critères de Chompret définissent les caractéristiques

\footnotetext{
${ }^{7}$ Communiqué de presse Unicancer, Groupe génétique et cancer : Quels gènes analyser face à un risque de cancer héréditaire du sein et de l'ovaire? http://www.unicancer.fr/actualites/groupe/quels-genesanalyser-risque-cancer-hereditaire-du-sein-ovaire ${ }^{\#}$.WgRfamrs0 04 .twitter

${ }^{8}$ La maladie de Cowden, ou syndrome des hamartomes multiples, est une maladie génétique rare, autosomique dominante, caractérisée par de multiples hamartomes sur le corps (à risque de transformation maligne), des lésions cutanéo-muqueuses pathognomoniques (kératoses, papules papillomateuses et des cas de syndromes de Lhermitte-Duclos avec gangliocytome dysplasique du cervelet). Elle prédispose à l'apparition de cancers et a pour origine des mutations du gène PTEN.

${ }^{9}$ Un syndrome polymalformatif rare révélé dans l'enfance par une macrocéphalie pathognomonique, chez le garçon par les lentigines du pénis, des lipomes sous-cutanés et viscéraux, des tumeurs hamartomateuses (polypes digestifs, hémangiomes), et des anomalies du système nerveux central dans $50 \%$ des cas.
}

$[72,73]$. Les mutations de ce gène confèrent un risque élevé de cancers du sein survenant à un âge très jeune (médiane de 25 ans) [74], associé à des sarcomes des tissus durs ou mous, des tumeurs cérébrales, des cortico-surrénalomes, toutes tumeurs d'association quasi pathognomoniques et de diagnostic en majorité très précoce, pouvant survenir dès l'enfance et avant 20 ans, et d'autres tumeurs solides, touchant la thyroïde, le poumon, le pancréas, l'estomac, ou les mélanomes et des leucémies [75].

Les patientes porteuses d'une mutation constitutionnelle de TP53 ont un risque relatif de cancer du sein, dans des familles $\mathrm{HBOC}$, proche de $4^{3}[21,22,76]$. Le niveau de risque chez les femmes porteuses d'une mutation du gène TP53 est ainsi considéré comme «très élevé $»^{3}$.

\section{Le gène $\mathrm{CDHl}$}

Le gène $\mathrm{CDHl}$ (cadherin 1) est un gène suppresseur de tumeurs situé sur le chromosome 16, qui code la $\varepsilon$-cadhérine impliquée dans l'adhérence des cellules épithéliales. Une mutation germinale du gène $\mathrm{CDHl}$ est à l'origine de cancers gastriques diffus héréditaires [77-79]. Les études estimant le risque de cancer de l'estomac chez les personnes porteuses de mutations du gène CDHl rapportent un risque élevé s'il y a des antécédents familiaux de cancers gastriques diffus (67\% pour les hommes et $83 \%$ pour les femmes [80]). En revanche, en l'absence d'antécédent familial de cancer gastrique diffus (CGD), le risque de cancer de l'estomac n'est pas connu car jamais rapporté.

Les études estimant le risque de cancer du sein chez les femmes porteuses de mutations du gène rapportent un risque très élevé, notamment de cancers lobulaires, similaire à celui observé chez les femmes porteuses de mutations des gènes BRCA1 ou BRCA2 [81, 82]. Le niveau de risque est considéré comme «très élevé » ${ }^{3}$.

\section{Le gène STKll}

Le gène STKIl (sérine/thréonine kinase 11) est un gène suppresseur de tumeurs situé sur le chromosome 19 , en $19 p 13.3$ [83]. II participe à la signalisation et à l'apoptose, et régule la voie mTOR (mammalian target of rapamycin). Une mutation germinale de STK11 est à l'origine du syndrome de Peutz-Jeghers ${ }^{10}$, et les patientes mutées présentent un risque augmenté de cancer colorectal, du sein, de l'intestin grêle, du pancréas, de l'estomac et de l'ovaire [84].

\footnotetext{
${ }^{10}$ Une pathologie autosomique dominante caractérisée par le développement de multiples polypes hamartomateux dans le tractus gastro-intestinal, avec une
} hyperpigmentation cutanée périorificielle caractéristique. 
Les études estimant le risque de cancer du sein chez les femmes porteuses de mutations du gène STKIl dans le cadre d'un syndrome de Peutz-Jeghers rapportent un risque très élevé (15\%) [85], et un risque cumulé à 70 ans de $45 \%$ [86], sans données disponibles pour des indications d'analyse du gène en dehors de ce syndrome. Il en va de même pour les études estimant le risque de cancer ovarien. L'analyse du gène STKII reste restreinte aux indications en rapport avec une symptomatologie évocatrice d'un syndrome de Peutz-Jeghers. Ces recommandations sont susceptibles d'évoluer; d'autres référentiels concluent de façon distincte ${ }^{11}[87,88]$.

Les gènes RAD51 C et D à haut risque de cancer de l'ovaire

Si en 2010, Meindl et al. [89] ont établi que le gène RAD51C était un gène de susceptibilité aux cancers dans des familles $H B O C$, très vite, les risques se sont affirmés pour une prédisposition héréditaire aux cancers ovariens pour les femmes porteuses de mutations touchant RAD51C [90] et RAD51D [91]. II n'apparaît cependant pas de différence de risque du cancer du sein par rapport à celui connu dans la population générale [76].

Les études estimant le risque de cancer ovarien chez les femmes porteuses de mutations des gènes RAD51C et RAD51D rapportent un sur risque du même ordre que celui connu pour le gène BRCA2 [90-92]. Les recommandations concernant les gènes $R A D 51 C$ et $R A D 51 D$ sont identiques, mais distinctes de celles du gène RAD51B [92].

\section{Les gènes de pénétrance modérée et de fréquence allélique haute ou faible}

La fréquence des mutations de ces gènes a été présentée en 2010 [93] : le risque relatif de cancer du sein selon ces mutations est compris entre 2 et 4 .

\section{Le gène CHعK2}

Le gène CHEK2 (checkpoint kinase 2) est un gène suppresseur de tumeur situé sur le chromosome 22 [94]. II code une sérine-thréonine kinase qui est activée lors de cassures double-brin de l'ADN et contribue à la transduction des signaux qui conduiront à la réparation de I'ADN [95, 96]. La protéine phosphoryle également BRCAl, facilitant son rôle dans la réparation de l'ADN [97].

La mutation germinale 1100 delC de CHEK2, fondatrice ${ }^{12}$ en Europe du Nord, augmente le risque de cancer du sein avec un risque relatif estimé à au moins 3 et un risque absolu de $29 \%$ à l'âge de 80 ans avec des cancers souvent bilatéraux, récidivants et de mauvais pronostic $[43,98]$. L'étendue des tumeurs peut inclure des tumeurs du côlon, de la prostate et, plus rarement, de l'ovaire. Plus récemment, une autre mutation récurrente de CHEK2, Y390C, a été retrouvée dans une population d'origine chinoise à haut risque de cancer du sein [99]. Le risque le plus important est cependant rapporté pour la mutation c. 1036 C>T [58].

${ }^{11}$ National Comprehensive Cancer Network (NCCN). Clinical practice guidelines in oncology - genetic/ familial high-risk assessment: Colorectal : https://www.nccn.org/professionals/physician_gls/default. asp $x^{\#}$ genetics_colon

${ }^{12}$ Mutation dont l'effet permet à l'individu qui en est porteur de se reproduire et donc de la transmettre.
Selon I'Unicancer, le niveau de risque chez les femmes porteuses de la délétion $1100 \mathrm{delC}$ et, par extrapolation, de toute mutation tronquante, est considéré comme «élevé ${ }^{3}$ et probablement majoré par une histoire familiale importante de cancer du sein. Il semble également justifié de prendre en considération le haut risque génétique dans le cas de la mutation c.1036 C>T, mais il n'y aurait pas de sur-risque de cancer de l'ovaire chez les femmes porteuses d'une mutation de ce gène. II a été cependant conclu à la non réalisation ou à l'arrêt de tests génétiques pré-symptomatiques dans les familles de ces patientes, bien que d'autres conclusions aient été différentes ${ }^{5}$. Les recommandations du Groupe Génétique et Cancer sont susceptibles d'évoluer.

\section{Le gène ATM}

Le gène ATM (ATM sérine/thréonine kinase) est situé sur le chromosome 11 . Il joue un rôle pivot dans la réparation de l'ADN et la progression du cycle cellulaire [100]. Une mutation germinale bi-allélique de ce gène est à l'origine du syndrome pédiatrique ataxie-télangiectasie à la révélation dans l'enfance, caractérisé par une ataxie cérébrale, des télangiectasies caractéristiques, une immunodéficience et un risque accru de tumeurs malignes, notamment mammaires et gastriques.

Actuellement, le groupe GGC d'Unicancer a établi les constatations suivantes:

- dans un contexte familial d'enfants atteints d'ataxietélangiectasie, le niveau de risque de cancer du sein chez les femmes porteuses d'une mutation du gène ATM semble élevé [101-108]. La mutation T7271G pourrait ainsi conférer un risque de cancer plus élevé, voisin de celui des mutations touchant les gènes BRCA [108-110]. Les premières observations publiées ont suggéré un risque associant d'autres tumeurs chez les porteurs hétérozygotes, comme le cancer de la vessie, des leucémies/ lymphomes, le cancer du pancréas (un risque qui semble corroboré par des observations plus récentes [111]), ainsi que le cancer gastrique [112]. II n'y a pas de données en faveur d'un sur-risque de cancer de l'ovaire.

- dans un contexte familial HBOC, il n'existe pas encore de données sur l'estimation de risque de cancer du sein chez les femmes porteuses d'une mutation touchant le gène ATM sans enfant atteint d'ataxie-télangiectasie $[53-56,113]$. Les données utilisant une variété de gènes mettent en évidence une grande diversité de mutations de type perte de fonction, avec une fréquence d'environ $1 \%$, ce qui correspond à $10 \%$ de la totalité des mutations délétères recensées ${ }^{13}$. II faut remarquer que la recommandation du NCCN américain (national

\footnotetext{
${ }^{13}$ Cohen-Haguenauer 0, Benkortebi R, Toledano D, et al. (2019, sous presse).
} 
comprehensive cancer network) est différente, au regard de la radiosensibilité présomptive qui oriente vers une surveillance systématique par IRM (imagerie par résonance magnétique) exclusive. Les recommandations du Groupe Génétique et Cancer sont susceptibles d'évoluer.

\section{Le gène BRIPI}

Le gène BRIPI (BRCAl-interacting protein C-terminal helicase 1) est situé sur le chromosome 17. II code la protéine BRIPl, un partenaire de liaison de BRCAl participant à la réparation des cassures double-brin de l'ADN [114]. Selon le GGC d'Unicancer, il n'y a pas de données suffisantes pour établir un risque augmenté de cancer de l'ovaire et/ou du sein sur la seule base d'une mutation hétérozygote identifiée sur ce gène. C'est donc l'histoire familiale qui prévaut : la prise en charge ovarienne en dépend après avis en réunions de concertations pluridisciplinaires. Unicancer a conclu à la non réalisation ou l'arrêt des tests génétiques présymptomatiques dans la famille. Cette recommandation est susceptible d'évoluer.

\section{Les gènes de faible pénétrance}

Des études d'association du génome entier (GWAS, genome wide association study) ont permis d'établir des associations entre des variations génétiques fréquentes, les polymorphismes (ou SNP, single nucleotide polymorphism), et une légère augmentation du risque de cancer du sein (risque relatif inférieur à 1,5 par rapport à la population générale) [93]. Ces études ont permis d'identifier des locus pour lesquels se dégagent de faibles augmentations du risque relatif de développer un cancer du sein dans la population générale. Chez les femmes jeunes, porteuses de mutations des gènes $B R C A$, et plus particulièrement du gène $B R C A 2$, la prise en compte de variants pourrait revêtir une significativité toute particulière, avec un effet cumulatif. L'effet modificateur peut se manifester de sorte que le risque cumulé à 70 ans évoluera, chez les femmes porteuses de mutations du gène BRCA2, de $41 \%$ pour les variants de FGFR2 (fibroblast growth factor receptor 2) et TOX3 (TOX high mobility group box family member 3 ) les plus anodins à $70 \%$ pour ceux dont l'effet paraît le plus délétère [93].

En conclusion, malgré des décennies de recherche, la mutation d'un gène causal n'est identifiée que dans moins de $20 \%$ des cas chez les patientes avec un contexte évocateur d'une prédisposition héréditaire : I'histoire familiale prévaut donc pour orienter la prise en charge ${ }^{1}$. Pour certains des gènes responsables, le niveau de risque encouru conduit, par contre, à préconiser des mesures de surveillance spécifiques, très attentives et régulières, voire des mesures de prévention.

\section{Le test génétique constitutionnel ou héréditaire ${ }^{14}$ : quand y recourir?}

Lors de l'interrogatoire initial, la recherche systématique des arguments pour une prédisposition génétique aux cancers et notamment des antécédents familiaux est nécessaire. La reconstitution de l'his-

\footnotetext{
${ }^{14}$ On distingue les tests qui apportent des informations sur le patrimoine génétique transmissible, présent dans toutes les cellules de l'organisme (génétique constitutionnelle), et les tests qui informent sur l'état du génome de cellules cancéreuses (génétique des tumeurs). Les tests de génétique constitutionnelle (ou héréditaire) reposent sur l'étude du patrimoine génétique d'une personne.
}

\begin{tabular}{|ll}
\hline Situation & Poids \\
\hline Mutation de BRCA identifiée dans la famille & 5 \\
\hline Cancer du sein chez femme $<30$ ans & 4 \\
\hline Cancer du sein chez femme 30 -40 ans & 3 \\
\hline Cancer du sein chez femme 40-50 ans & 2 \\
\hline Cancer du sein chez femme 50-70 ans & 1 \\
\hline Cancer du sein chez l'homme & 4 \\
\hline Cancer ovarien & 3 \\
\hline Indication & \\
\hline 5 : excellente & \\
\hline 3-4 : indication possible & < : intérêt faible \\
\hline
\end{tabular}

Tableau I. Score d'Eisinger ou score Inserm. II s'agit d'un score d'orientation vers une consultation d'oncogénétique, de calcul simple, très largement utilisé et auquel il est fait référence dans les recommandations de la HAS 2014 relatives à la prise en charge des femmes à risque élevé de cancer du sein.

toire familiale est donc primordiale avec, si possible, le recueil des dossiers familiaux. Les éléments qui orienteront vers une consultation d'oncogénétique seront (1) la présence de plusieurs cas de cancer du sein dans une branche familiale, qu'il s'agisse du côté paternel ou maternel ; (2) la précocité de survenue du cancer ; (3) un cancer multifocal et/ou bilatéral ; (4) la présence d'un cancer de l'ovaire; (5) la survenue d'un cancer du sein chez l'homme; plus rarement, un cancer du pancréas, un mélanome ou un cancer de la prostate (Tableau I) [115].

Des critères spécifiques ont aussi été retenus par l'INCa pour proposer un test génétique, sur la base d'une histoire familiale ou personnelle (Tableau II).

Comment le test génétique est-il mis en œuvre?

Pour les gènes mutés qui sont transmis, toutes les cellules de l'organisme porteront cette version du génome ${ }^{15}$. L'anomalie pourra donc être détectée par une simple prise de sang (ou biopsie liquide). II s'agira d'un test dit «constitutionnel » qui sera proposé lorsqu'un risque héréditaire est soupçonné dans une famille. II sera réalisé sur l'ADN «germinal», isolé à partir de cellules nontumorales, les leucocytes circulants. Le prélèvement de contrôle obligatoire peut être un frottis jugal. La recherche

\footnotetext{
${ }^{15}$ La situation complexe des mosaïques ne sera pas abordée.
} 


\section{Critères familiaux}

Selon l'expertise nationale de 1998 mise à jour en 2004 [115] :

- Au moins trois cas de cancers du sein diagnostiqués chez les apparentés au premier ou au second degré, appartenant à une même branche parentale (quels que soient les âges au diagnostic)

- Deux cas de cancers diagnostiqués chez les apparentés au premier degré ou second degré passant par un homme, si :

- un cancer du sein avant 40 ans ou un cancer du sein bilatéral

- un cancer du sein chez l'homme

- un cancer du sein et un cancer de l'ovaire (quel que soit l'âge)

- deux cancers de l'ovaire (quel que soit l'âge)

Ces critères sont actuellement étendus aux situations suivantes :

- Au moins deux cas de cancer du sein ou de l'ovaire et au moins un cancer du pancréas chez des apparentés au premier degré ou au second degré, appartenant à une même branche parentale (quels que soient les âges au diagnostic)

\section{Critères individuels}

- un cancer du sein infiltrant isolé avant 36 ans

- un cancer du sein et un cancer de l'ovaire chez la même femme (quel que soit l'âge)

- un cancer du sein triple négatif ou médullaire avant 51 ans

- un cancer du sein chez l'homme (quel que soit l'âge)

- un cancer de l'ovaire ou tubaire avant 70 ans (non mucineux) et sans limite d'âge en cas d'histologie « cancer séreux haut grade »

Tableau II. Critères d'indication au test génétique constitutionnel (www.ecancer.fr).

de mutation en cause est mise en œuvre chez une personne atteinte de cancer (le cas-index). Cette mutation peut être située n'importe où sur le gène, elle est donc souvent différente d'une famille à une autre. Dans le cas particulier des hémopathies malignes où de nombreuses cellules tumorales circulent dans le sang, la confirmation d'une mutation constitutionnelle nécessite une biopsie de peau (test sur fibroblastes).

\section{La grande variabilité des mutations}

L'étape limitant les tests de prédisposition est l'identification de l'altération génétique qui est responsable dans la famille concernée. Plus de 1000 différentes orthographes mutationnelles délétères ont ainsi été identifiées pour chacun des gènes BRCAl et BRCA2 (Figure $3 A, B$ ). Ces analyses sont donc très complexes et nécessitent un certain temps (en moyenne 6 à 9 mois dans le contexte du dispositif national d'oncogénétique) - un délai qu’il serait bon de réduire à 3 à 4 mois.

\section{Les mutations délétères}

S'agissant des seuls gènes BRCA1 et BRCA2, plus de 2600 mutations différentes sont enregistrées dans la base de données du National Institute of Health aux États-Unis (BIC, breast cancer information core) ${ }^{16}$ [116] et dans la base BRCAshare issue de la cohorte française GENEPSO du Groupe génétique et cancer d'Unicancer [117]. La grande diversité de ces mutations et leur distribution le long de ces gènes rendent difficile la recherche initiale de la mutation dans une famille donnée. Cependant, des mutations récurrentes ont été décrites dans certaines populations: - La délétion c.68_69delAG et l'insertion c.5266dupC de BRCAl et la délétion c.5946delT de BRCA2 dans la population d'origine juive ashkénaze [118].

\footnotetext{
${ }^{16}$ Breast cancer information core (BIC): https://research.nhgri.nih.gov/bic/
}

- La délétion c.3481_3491delll et le variant c.5128G>T (p.Gly1710Trp), dont on observe une plus grande proportion dans la région Nord- $\varepsilon$ st de la France avec, en particulier, la délétion c.3481_3491dell1 en AlsaceLorraine [119].

\section{Variants de signification indéterminée (VSI)}

Plon et al. [120] ont proposé en 2008 une classification des variants selon 5 classes, les variants de classe 5 étant considérés comme délétères. Si environ $70 \%$ des variations identifiées sur les gènes $B R C A 1$ et BRCA2 sont de type 4 ou 5 , des variants de classe 3 de signification indéterminée, et pour lesquels il est impossible d'établir formellement le statut délétère, sont régulièrement retrouvés. C'est le cas des variants génomiques rares, faux sens ou non-codants, en l'absence d'enquête familiale et de caractérisation fonctionnelle. L'étude nationale COVAR (étude de coségrégation familiale des variants nucléotidiques dans les gènes BRCAl/2 et, désormais, PALB2) coordonnée par l'Institut Curie (Paris, France), a pour objectif de contribuer à résoudre ces ambiguïtés. Cette initiative est relayée au plan international par le consortium ENIGMA [121, 122]. L'objectif est de définir le caractère délétère ou non de ces variations par l'analyse de leur co-ségrégation familiale avec la maladie: apparentés atteints de cancer du sein et/ou de l'ovaire, porteurs des variants de signification inconnue et apparentés indemnes de cancer non porteurs. II s'agira de pouvoir valider ou non l'utilisation de ces variants pour le conseil génétique. 
Le cas-index : l'individu de la famille qui doit être testé en premier Le médecin oncogénéticien propose un test génétique constitutionnel en choisissant un cas-index, c'est-à-dire le sujet dont l'analyse peut conduire au résultat le plus pertinent au bénéfice de l'ensemble de la branche familiale concernée. Le consentement éclairé obligatoirement signé par la personne testée est recueilli après remise d'une note d'information expliquée au préalable. Un accompagnement psychologique est systématiquement proposé. Les résultats, confidentiels, sont rendus par l'oncogénéticien lors d'un entretien individuel qui fait l'objet d'une consultation obligatoire.

Un tableau est remis au cas-index. II indique ses apparentés qui sont susceptibles de partager la mutation qui a été identifiée dans son génome. La personne dépistée et porteuse de la mutation génétique sera dans l'obligation d'informer ses apparentés de la mise à disposition d'un test prédictif ou, à défaut d'adhésion de cette personne au test génétique constitutionnel, à la nécessité d'une surveillance annuelle à haut risque génétique ${ }^{17}$. Le cas-index peut cependant déléguer cette tâche à l'équipe d'oncogénétique qui doit alors informer les apparentés concernés en formulant les informations clé ; l'identité du cas-index pouvant rester anonyme.

\section{Élargissement du spectre des gènes analysés chez le cas-index: les panels multigènes}

Les progrès technologiques les plus récents permettent aujourd'hui de rechercher des mutations sur plusieurs gènes de façon simultanée. Ainsi, en une seule analyse, des données qui portent sur un ensemble de gènes susceptibles d'intervenir dans la prédisposition au cancer peuvent être obtenues. Ces nouvelles techniques (NGS, next generation sequencing) de séquençage à haut débit permettent de tester l'ensemble des gènes susceptibles d'intervenir dans la prédisposition au cancer du sein [48, 52-61]. L'analyse actuellement réalisée, dite en panels multigènes, est notamment étendue aux gènes impliqués dans la recombinaison homologue $[5,9]$, dont les gènes majeurs, $B R C A 1, B R C A 2$ ou PALB2. Selon l'expertise conduite par Unicancer, une analyse de 13 gènes est recommandée ${ }^{7,13}$ [64]. Selon le gène concerné, le niveau de risque de cancer varie. Les dispositions de prise en charge préconisées pourront donc être modulées en fonction du gène muté et des progrès de nos connaissances, au fur et à mesure de l'expérience accumulée au niveau international. Il faut souligner l'importance conjointe et prédominante de l'histoire familiale selon les recommandations de la Haute autorité de santé de $2014^{3}$.

\section{Quand le test génétique revêt un caractère d'urgence}

L'utilisation du test génétique en urgence se vérifie particulièrement quand son résultat peut avoir un impact sur le choix des modalités du traitement chirurgical ou des conséquences sur le traitement médical de la patiente: selon la sensibilité aux sels de platine, dans le cas des tumeurs du sein triple-négatives ou, de façon imminente, pour la prescription de thérapies ciblées comme avec les inhibiteurs enzymatiques

${ }^{17}$ Décret $n^{\circ} 2013-527$ du 20 juin 2013 des lois de bioéthique portant sur les tests constitutionnels prédictifs. des poly(ADP-ribose) polymérases (PARP) seuls ou en association avec une immunothérapie, qui font actuellement l'objet d'essais cliniques.

\section{Les tests pré-symptomatiques}

Dans l'éventualité où une mutation a été mise en évidence, elle peut être recherchée chez les personnes apparentées qui n’ont pas développé de cancer. Si une altération génétique est identifiée, celle-ci constituera la clé du code sur laquelle un test génétique pourra être proposé aux autres membres de la famille qui le souhaitent. La mise en œuvre du test nécessite deux prélèvements (le second à des fins de vérification) et une consultation, systématiquement proposée, auprès d'un psychologue. Le résultat individuel sera communiqué dans le cadre d'une consultation oncogénétique. Dans ce contexte, dit prédictif ou ciblé, un résultat négatif prend toute sa signification: le sujet testé n'est pas porteur de la prédisposition identifiée dans la famille. Les femmes, qui ne portent pas la mutation héréditaire familiale, auront donc un risque de cancer du sein comparable à la population générale, soit environ $10 \%$ pour la vie entière. En revanche, les femmes qui ont hérité de la mutation auront un risque qui peut atteindre 60 à $80 \%$ de développer un cancer du sein au cours de leur vie : elles auront donc besoin d'une prise en charge appropriée. Dans certains cas, des tumeurs de diagnostic précoce sont relevées malgré l'absence de mutation familiale : on parle de «phénocopie».

Il se peut qu'aucune altération génétique ne soit identifiée chez le (ou les) cas index. Cela peut être lié à une anomalie non décelable par nos techniques actuelles, à une anomalie qui se situerait sur un gène que nous ne connaissons pas encore, ou parce qu'il n'y a pas d'anomalie génétique dans la famille. Un résultat négatif diminue le risque d'existence d'une prédisposition dans la famille. II ne l'élimine pas définitivement. Même avec les derniers progrès technologiques, il est possible que certaines mutations échappent à nos analyses. L'approfondissement des données recueillies sur l'arbre généalogiques peut alors parfois aboutir à une syndrômologie évocatrice et orienter secondairement vers des tests génétiques constitutionnels complémentaires. Des tests de recherche peuvent également être envisagés dans l'éventualité où l'agrégation familiale de cancer du sein est particulièrement saillante: c'est dans ce cas que le déploiement des technologies de séquençage est programmé par le Plan France médecine génomique $2025^{18}$, par l'analyse d'exomes (WES) et/ou l'analyse pan-génome (WGS) afin

\footnotetext{
18 Plan France Médecine génomique 2025 - https://solidarites-sante.gouv.fr/
} systeme-de-sante-et-medico-social/recherche-et-innovation/france-genomique 

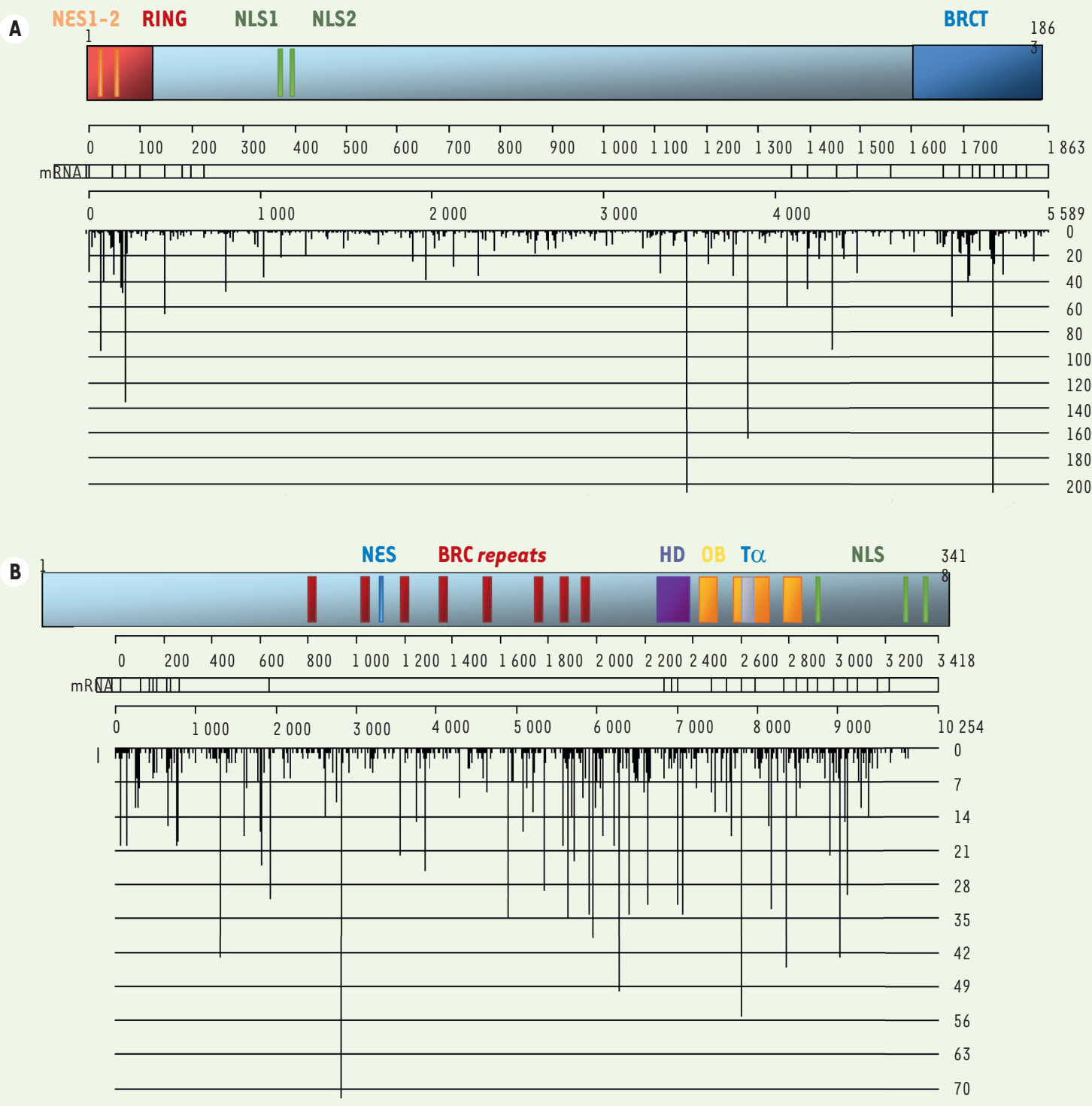

Figure 3. Mutations causales identifiées pour les gènes BRCA1 (A) et BRCA2 (B) dans la base internationale BIC et la base de données française. $\varepsilon$ n 2014, près de 700 mutations différentes ont été dénombrées par la base française dans les gènes BRCAl et BRCA2 au sein de plus de 3500 et 2500 familles portant respectivement une mutation inactivatrice du gène BRCAl ou BRCA2 (d'après http://www.umd.be/BRCAl/ et http://www. umd.be/BRCA2/).

de découvrir de nouveaux gènes de prédisposition, ou de rechercher de nouveaux modèles (polygéniques) de prédisposition.

Dans les cas où l'histoire familiale est indicative de prédispositions mais avec une recherche de mutations qui s'avère négative et donc sans indication de tests constitutionnels complémentaires, notamment avec des cancers de diagnostic précoce, les recommandations de prise en charge et de suivi des personnes ont été définies par la Haute autorité de santé en mai 2014, en tenant compte de l'histoire familiale ${ }^{1}$. La consultation d'oncogénétique contribue alors à évaluer un risque individuel pour en tirer les conséquences les mieux adaptées. La conduite pratique tient compte de multiples facteurs tant fami- liaux (types de cancer, âge de survenue, gravité, etc.) qu'individuels (âge, situation familiale, préférences personnelles, antécédents, etc.). Ces éléments entrent en considération dans l'évaluation du risque. $\diamond$

\section{SUMMARY}

Hereditary predisposition to breast cancer ( 1 ): genetics The main objective of oncogenetics is to characterize a subpopulation of patients at high risk of cancer development at an early age in order to provide specific recommendations for an optimized follow-up and care path. 
Oncogenetic counselling helps to assess individual risk from a family history. By a family approach of formal genetics, the key issue is to identify families with a strong aggregation of cancers, and, in particular, suggesting a specific syndrome of inherited predisposition to cancer. This approach can lead to the proposal of germline genetic testing in search of causal mutations. As up to know, the search for a constitutional mutation in the BRCA genes has led to the identification of a causal deleterious mutation in less than $10 \%$ of index-cases analyzed. It is therefore important to evaluate the impact of new genes in the current panorama of inherited predisposition to breast and ovarian cancer. $\diamond$

\section{REMERCIEMENTS}

À Dominique Stoppa-Lyonnet pour sa contribution aux schémas directeurs de la Figure 3.

\section{LIENS D'INTÉRÊT}

L'auteure déclare n'avoir aucun lien d'intérêt concernant les données publiées dans cet article.

\section{RéFÉRENCES}

1. Ford D, Easton DF, Stratton M, et al. Genetic heterogeneity and penetrance analysis of the BRCAl and BRCA2 genes in breast cancer families. The Breast cancer linkage consortium. Am J Hum Genet $1998 ; 62: 676-89$.

2. Hall JM, Lee MK, Newman B, et al. Linkage of early-onset familial breast cancer to chromosome $17 q 21$. Science $1990 ; 250: 1684-9$.

3. Miki Y, Swensen J, Shattuck-Eidens D, et al. A strong candidate for the breast and ovarian cancer susceptibility gene BRCAl. Science $1994 ; 266: 66-71$.

4. Wooster R, Neuhausen SL, Mangion J, et al. Localization of a breast cancer susceptibility gene, BRCA2, to chromosome 13q12-13. Science 1994 ; $265: 2088-90$.

5. D’Andrea AD, Grompe M. The Fanconi anaemia/BRCA pathway. Nat Rev Cancer 2003 ; 3 : 23-34.

6. West SC. Molecular views of recombination proteins and their control. Nat Rev Mol Cell Biol 2003 ; $4: 435-45$.

7. Howlett NG, Taniguchi T, Olson S, et al. Biallelic inactivation of BRCA2 in Fanconi anemia. Science $2002 ; 297: 606-9$.

8. Gudmundsdottir K, Ashworth A. The roles of BRCAl and BRCA2 and associated proteins in the maintenance of genomic stability. Oncogene $2006 ; 25: 5864-74$.

9. D’Andrea A. Susceptibility pathways in Fanconi's anemia and breast cancer. N Engl J Med 2010 ; 362 : 1909-19.

10. Roy R, Chun J, Powell SN. BRCAl and BRCA2: different roles in a common pathway of genome protection. Nat Rev Cancer $2011 ; 12: 68-78$.

11. Hakem R, de la Pompa JL, Sirard C, et al. The tumor suppressor gene Brcal is required for embryonic cellular proliferation in the mouse. Cell 1996; 85 : 1009-23.

12. Patel KJ, Yu VP, Lee $H$, et al. Involvement of Brca2 in DNA repair. Mol Cell $1998 ; 1: 347-57$.

13. Liu J, Doty T, Gibson B, Heyer WD. Human BRCA2 protein promotes RAD51 filament formation on RPA-covered single-stranded DNA. Nat Struct Mol Biol $2010 ; 17: 1260-2$.

14. Kinzler KW, Vogelstein B. Cancer-susceptibility genes. Gatekeepers and caretakers. Nature 1997 ; $386: 761-3$.

15. Rosen EM, Fan S, Ma Y. BRCAl regulation of transcription. Cancer Lett $2006 ; 236: 175-85$.

16. Knudson AG. Mutation and cancer: statistical study of retinoblastoma. Proc Natl Acad Sci USA $1971 ; 68: 820-3$.

17. Antoniou A, Pharoah PD, Narod $S$, et al. Average risks of breast and ovarian cancer associated with BRCAl or BRCA2 mutations detected in case series unselected for family history: a combined analysis of 22 studies. Am J Hum Genet $2003 ; 72$ : 1117-30.

18. King MC, Marks JH, Mandell JB, New York Breast Cancer Study Group. Breast and ovarian cancer risks due to inherited mutations in BRCAl and BRCA2. Science 2003 ; 302 : 643-6.

19. Chen S, Parmigiani G. Meta-analysis of BRCAl and BRCA2 penetrance.J Clin Oncol 2007 ; 25 : 1329-33.

20. Rebbeck TR, Mitra N, Wan F, et al. Association of type and location of BRCAl and BRCA2 mutations with risk of breast and ovarian cancer. JAMA $2015 ; 313: 1347-61$.

21. Kuchenbaecker KB, McGuffog L, Barrowdale D, et al. Evaluation of polygenic risk scores for breast and ovarian cancer risk prediction in BRCAl and BRCA2 mutation carriers. J Natl Cancer Inst 2017; 109.

22. Kuchenbaecker KB, Hopper JL, Barnes DR, et al. Risks of breast, ovarian, and contralateral breast cancer for BRCAl and BRCA2 mutation carriers. JAMA $2017 ; 317: 2402-16$.

23. Klein AP. Genetic susceptibility to pancreatic cancer. Mol Carcinog $2012 ; 51: 14-24$.

24. Ginsburg OM, Kim-Sing C, Foulkes WD, et al. BRCAl and BRCA2 families and the risk of skin cancer. Fam Cancer $2010 ; 9: 489-93$.

25. Couch FJ, Farid LM, DeShano ML, et al. BRCA2 germline mutations in male breast cancer cases and breast cancer families. Nat Genet $1996 ; 13: 123-5$.
26. Kote-Jarai Z, Leongamornlert $D$, Saunders $\varepsilon$, et al. BRCA2 is a moderate penetrance gene contributing to young-onset prostate cancer: implications for genetic testing in prostate cancer patients. BrJ Cancer $2011 ; 105$ : $1230-4$.

27. Castro $\varepsilon$, Goh C, Olmos D, et al. Germline BRCA mutations are associated with higher risk of nodal involvement, distant metastasis, and poor survival outcomes in prostate cancer. J Clin Oncol 2013 ; 31 : 1748-57.

28. Cussenot 0 . Management of prostate cancer: the new challenges. Presse Med 2017 ; 46 : 923-7.

29. Moran A, O'Hara C, Khan S, et al. Risk of cancer other than breast or ovarian in individuals with BRCAl and BRCA2 mutations. Fam Cancer $2012 ; 11: 235-42$.

30. Mersch J, Jackson MA, Park M, et al. Cancers associated with BRCAl and BRCA2 mutations other than breast and ovarian. Cancer 2015; $121: 269-75$.

31. Eerola H, Heikkila P, Tamminen A, et al. Relationship of patients'age to histopathological features of breast tumours in BRCAl and BRCA2 and mutation-negative breast cancer families. Breast Cancer Res $2005 ; 7$ : R465-9.

32. Chappuis PO, Nethercot V, Foulkes WD. Clinico-pathological characteristics of BRCA1- and BRCA2-related breast cancer. Semin Surg Oncol $2000 ; 18$ : 287-95.

33. Lakhani SR, Gusterson BA, Jacquemier J, et al. The pathology of familial breast cancer: histological features of cancers in families not attributable to mutations in BRCAl or BRCA2. Clin Cancer Res $2000 ; 6: 782-9$.

34. Foulkes WD, Stefansson IM, Chappuis PO, et al. Germline BRCAl mutations and a basal epithelial phenotype in breast cancer. J Natl Cancer Inst 2003 ; $95: 1482-5$.

35. Foulkes WD, Smith IE, Reis-Filho JS. Triple-negative breast cancer. $N$ Engl J Med $2010 ; 363: 1938-48$.

36. Mavaddat N, Pharoah PD, Blows F, et al. Familial relative risks for breast cancer by pathological subtype: a population-based cohort study. Breast Cancer Res $2010 ; 12$ : R10.

37. Lakhani SR, Van De Vijver MJ, Jacquemier J, et al. The pathology of familial breast cancer: predictive value of immunohistochemical markers estrogen receptor, progesterone receptor, $\mathrm{HER}-2$, and $\mathrm{p} 53$ in patients with mutations in BRCAl and BRCA2. J Clin Oncol $2002 ; 20: 2310-8$.

38. Bane AL, Beck JC, Bleiweiss I, et al. BRCA2 mutation-associated breast cancers exhibit a distinguishing phenotype based on morphology and molecular profiles from tissue microarrays. Am J Surg Pathol 2007 ; 31 : 121-8.

39. Agnarsson BA, Jonasson JG, Bjornsdottir IB, et al. Inherited BRCA2 mutation associated with high grade breast cancer. Breast Cancer Res Treat 1998 ; $47: 121-7$.

40. Palacios J, Robles-Frias MJ, Castilla MA, et al. The molecular pathology of hereditary breast cancer. Pathobiology $2008 ; 75: 85-94$.

41. Palacios J, Honrado $\varepsilon$, Osorio A, et al. Immunohistochemical characteristics defined by tissue microarray of hereditary breast cancer not attributable to BRCAl or BRCA2 mutations: differences from breast carcinomas arising in BRCAl and BRCA2 mutation carriers. Clin Cancer Res $2003 ; 9$ : 3606-14.

42. Copson ER, Maishman TC, Tapper WJ, et al. Germline BRCA mutation and outcome in young-onset breast cancer (POSH): a prospective cohort study. Lancet Oncol $2018 ; 19$ : 169-80.

43. Easton DF, Pharoah PD, Antoniou AC, et al. Gene-panel sequencing and the prediction of breast-cancer risk. $N$ Engl J Med 2015 ; 372 : 2243-57.

44. Buisson R, Dion-Cote AM, Coulombe Y, et al. Cooperation of breast cancer proteins PALB2 and piccolo BRCA2 in stimulating homologous recombination. Nat Struct Mol Biol $2010 ; 17$ : 1247-54.

45. Buisson R, Niraj J, Pauty J, et al. Breast cancer proteins PALB2 and BRCA2 stimulate polymerase eta in recombination-associated DNA synthesis at blocked replication forks. Cell Rep $2014 ; 6$ : 553-64.

46. Reid S, Schindler D, Hanenberg $\mathrm{H}$, et al. Biallelic mutations in PALB2 cause Fanconi anemia subtype FA-N and predispose to childhood cancer. Nat Genet 2007 ; 39 : 162-4.

47. Antoniou AC, Foulkes WD, Tischkowitz M. Breast-cancer risk in families with mutations in PALB2. N Engl J Med 2014 ; 371 : 1651-2.

48. Casadei $S$, Norquist BM, Walsh T, et al. Contribution of inherited mutations in the BRCA2-interacting protein PALB2 to familial breast cancer. Cancer Res $2011 ; 71: 2222-9$.

49. Tischkowitz M, Capanu M, Sabbaghian N, et al. Rare germline mutations in PALB2 and breast cancer risk: a population-based study. Hum Mutat 2012 ; $33: 674-80$.

50. Erkko H, Dowty JG, Nikkila J, et al. Penetrance analysis of the PALB2 c.1592delT founder mutation. Clin Cancer Res 2008 ; 14 : 4667-71. 


\section{RÉFÉRENCES}

51. Heikkinen T, Karkkainen H, Aaltonen $\mathrm{K}$, et al. The breast cancer susceptibility mutation PALB2 1592 delT is associated with an aggressive tumor phenotype. Clin Cancer Res $2009 ; 15$ : 3214-22.

52. Thompson $\varepsilon R$, Rowley SM, Li N, et al. Panel testing for familial breast cancer: calibrating the tension between research and clinical care. J Clin Oncol 2016 ; 34 : 1455-9.

53 Couch FJ, Shimelis H, Hu C, et al. Associations between cancer predisposition testing panel genes and breast cancer. JAMA Oncol 2017 ; 3 : 1190-6.

54. Buys SS, Sandbach JF, Gammon A, et al. A study of over 35,000 women with breast cancer tested with a 25-gene panel of hereditary cancer genes. Cancer $2017 ; 123: 1721-30$.

55. Tung $\mathrm{N}$, Battelli $\mathrm{C}$, Allen $\mathrm{B}$, et al. Frequency of mutations in individuals with breast cancer referred for BRCAl and BRCA2 testing using next-generation sequencing with a 25 -gene panel. Cancer $2015 ; 121: 25-33$

56. Castera L, Krieger S, Rousselin A, et al. Next-generation sequencing for the diagnosis of hereditary breast and ovarian cancer using genomic capture targeting multiple candidate genes. EurJ Hum Genet 2014 ; 22 : 1305-13.

57. Southey MC, Teo ZL, Dowty JG, et al. A PALB2 mutation associated with high risk of breast cancer. Breast Cancer Res $2010 ; 12$ : R109.

58. Southey MC, Goldgar DE, Winqvist R, et al. PALB2, CHEK2 and ATM rare variants and cancer risk: data from COGS. J Med Genet $2016 ; 53: 800-11$

59. Ramus SJ, Song H, Dicks $\varepsilon$, et al. Germline mutations in the BRIP1, BARD1, PALB2, and NBN genes in women with ovarian cancer. J Natl Cancer Inst $2015 ; 107$.

60. Rosenthal ET, Bernhisel R, Brown K, et al. Clinical testing with a panel of 25 genes associated with increased cancer risk results in a significant increase in clinically significant findings across a broad range of cancer histories. Cancer Genet 2017 ; 218-219 : 58-68.

61. Kurian AW, Ward KC, Hamilton AS, et al. Uptake, results, and outcomes of germline multiple-gene sequencing after diagnosis of breast cancer. JAMA Oncol 2018;4:1066-72.

62. Cybulski C, Kluzniak W, Huzarski T, et al. Clinical outcomes in women with breast cancer and a PALB2 mutation: a prospective cohort analysis. Lancet Oncol 2015 ; 16 : 638-44.

63. Jones $\mathrm{S}$, Hruban RH, Kamiyama M, et al. Exomic sequencing identifies PALB2 as a pancreatic cancer susceptibility gene. Science $2009 ; 324: 217$.

64. Moretta-Serra J, Berthet P, Bonadona V, et al. Recommandation française pour l'analyse en pane de gènes dans la cadre de la prédisposition héréditaire au cancer du sein ou de l'ovaire. Quels gènes analyser? Pour quelle utilité clinique? Bull Cancer 2018 ; 105 : 907-17.

65. Nelen MR, Padberg GW, Peeters $\varepsilon A$, et al. Localization of the gene for Cowden disease to chromosome 10q22-23. Nat Genet $1996 ; 13: 114-6$.

66. Hopkins BD, Parsons RE. Molecular pathways: intercellular PTEN and the potential of PTEN restoration therapy. Clin Cancer Res $2014 ; 20: 5379-83$.

67. Uppal S, Mistry D, Coatesworth AP. Cowden disease: a review. Int J Clin Pract 2007 ; 61 : 645-52.

68. Pilarski R, Stephens JA, Noss R, et al. Predicting PTEN mutations: an evaluation of Cowden syndrome and Bannayan-Riley-Ruvalcaba syndrome clinical features. J Med Genet 2011 ; 48 505-12.

69. Schrager CA, Schneider D, Gruener AC, et al. Clinical and pathological features of breast disease in Cowden's syndrome: an underrecognized syndrome with an increased risk of breast cancer. Hum Pathol $1998 ; 29: 47-53$.

70. Bubien V, Bonnet F, Brouste V, et al. High cumulative risks of cancer in patients with PTEN hamartoma tumour syndrome.J Med Genet $2013 ; 50: 255-63$.

71. Ngeow J, Sesock K, Eng C. Breast cancer risk and clinical implications for germline PTEN mutation carriers. Breast Cancer Res Treat 2017 ; $165: 1-8$.

72. Li FP, Fraumeni JF Jr, Mulvihill JJ, et al. A cancer family syndrome in twenty-four kindreds. Cancer Res $1988 ; 48: 5358-62$.

73. Bougeard G, Renaux-Petel M, Flaman JM, et al. Revisiting Li-Fraumeni syndrome from TP53 mutation carriers. J Clin Oncol $2015 ; 33: 2345-52$.

74. Masciari S, Dillon DA, Rath M, et al. Breast cancer phenotype in women with TP53 germline mutations: a Li-Fraumeni syndrome consortium effort. Breast Cancer Res Treat 2012 ; 133 : 1125-30.

75. Gonzalez KD, Noltner KA, Buzin CH, et al. Beyond Li Fraumeni syndrome: clinical characteristics of families with $\mathrm{p} 53$ germline mutations. J Clin Oncol $2009 ; 27$ : 1250-6.

76. Li J, Meeks H, Feng BJ, et al. Targeted massively parallel sequencing of a panel of putative breast cancer susceptibility genes in a large cohort of multiple-case breast and ovarian cancer families. J Med Genet $2016 ; 53: 34-42$.

77. Guilford PJ, Hopkins JB, Grady WM, et al. $\varepsilon$-cadherin germline mutations define an inherited cancer syndrome dominated by diffuse gastric cancer. Hum Mutat $1999 ; 14: 249-55$.

78. Huntsman DG, Carneiro F, Lewis FR, et al. Early gastric cancer in young, asymptomatic carriers of germ-line $\varepsilon$-cadherin mutations. N EnglJ Med 2001 ; 344 : 1904-9.

79. Fitzgerald RC, Hardwick R, Huntsman D, et al. Hereditary diffuse gastric cancer: updated consensus guidelines for clinical management and directions for future research. J Med Genet $2010 ; 47: 436-44$

80. Pharoah PD, Guilford P, Caldas C, International Gastric Cancer Linkage. Incidence of gastric cance and breast cancer in $\mathrm{CDHl}$ ( $\varepsilon$-cadherin) mutation carriers from hereditary diffuse gastric cancer families. Gastroenterology $2001 ; 121: 1348-53$.

81. Benusiglio PR, Malka D, Rouleau $\varepsilon$, et al. $\mathrm{CDHl}$ germline mutations and the hereditary diffuse gastric and lobular breast cancer syndrome: a multicentre study. J Med Genet 2013 ; 50 : 486-9.
82. Hansford $\mathrm{S}$, Kaurah $\mathrm{P}$, Li-Chang $\mathrm{H}$, et al. Hereditary diffuse gastric cancer syndrome: $\mathrm{CDH} 1$ mutations and beyond. JAMA Oncol $2015 ; 1: 23-32$.

83. Hemminki A, Tomlinson I, Markie D, et al. Localization of a susceptibility locus for Peutz-Jeghers syndrome to $19 \mathrm{p}$ using comparative genomic hybridization and targeted linkage analysis. Nat Genet 1997 ; 15 : 87-90.

84. Schumacher V, Vogel T, Leube B, et al. STK1l genotyping and cancer risk in Peutz-Jeghers syndrome.J Med Genet 2005 ; 42 : 428-35.

85. Giardiello FM, Brensinger JD, Tersmette AC, et al. Very high risk of cancer in familial Peutz-Jeghers syndrome. Gastroenterology $2000 ; 119$ : 1447-53.

86. Hearle N, Schumacher V, Menko FH, et al. Frequency and spectrum of cancers in the Peutz-Jeghers syndrome. Clin Cancer Res 2006; 12:3209-15.

87. Beggs AD, Latchford AR, Vasen HF, et al. Peutz-Jeghers syndrome: a systematic review and recommendations for management. Gut $2010 ; 59$ : 975-86.

88. van Lier MG, Wagner A, Mathus-Vliegen EM, et al. High cancer risk in PeutzJeghers syndrome: a systematic review and surveillance recommendations. Am J Gastroenterol 2010 ; 105 : 1258-64.

89. Meindl A, Hellebrand H, Wiek C, et al. Germline mutations in breast and ovarian cancer pedigrees establish RAD51C as a human cancer susceptibility gene. Nat Genet $2010 ; 42: 410-4$.

90. Song H, Dicks $\varepsilon$, Ramus SJ, et al. Contribution of germline mutations in the RAD51B, RAD51C, and RAD51D genes to ovarian cancer in the population.J Clin Oncol $2015 ; 33: 2901-7$.

91. Loveday C, Turnbull C, Ramsay $\varepsilon$, et al. Germline mutations in RAD51D confer susceptibility to ovarian cancer. Nat Genet $2011 ; 43: 879-82$.

92. Sopik V, Akbari MR, Narod SA. Genetic testing for RAD51C mutations: in the clinic and community. Clin Genet $2015 ; 88$ : 303-12.

93. Cohen-Haguenauer 0 . Quantification du risque individuel de cancer du sein chez la femme jeune. In : Anne Lesur BC, Jean-Pierre Bellocq, Béatrice Gairard, eds. La femme jeune face au cancer du sein. Actes de la 32 Journées de la Société Française de Sénologie et de Pathologie Mammaire, Strasbourg $2010: 92-107$

94. Bell DW, Varley JM, Szydlo TE, et al. Heterozygous germ line hCHK2 mutations in Li-Fraumeni syndrome. Science 1999 ; $286: 2528-31$.

95. Shieh Sy, Ahn J, Tamai K, et al. The human homologs of checkpoint kinases Chk1 and Cdsl (Chk2) phosphorylate p53 at multiple DNA damage-inducible sites. Genes Dev 2000 ; $14: 289-300$.

96. Falck J, Mailand N, Syljuasen RG, et al. The ATM-Chk2-Cdc25A checkpoint pathway guards against radioresistant DNA synthesis. Nature $2001 ; 410$ : 842-7.

97. Lee JS, Collins KM, Brown AL, et al. hCdsl-mediated phosphorylation of BRCAl regulates the DNA damage response. Nature $2000 ; 404$ : 201-4.

98. Weischer M, Nordestgaard BG, Pharoah P, et al. CHEK2*1100delC heterozygosity in women with breast cancer associated with early death, breast cancer-specific death, and increased risk of a second breast cancer. J Clin Oncol 2012 ; 30 : 4308-16.

99. Wang N, Ding H, Liu C, et al. A novel recurrent CHEK2 Y390C mutation identified in high-risk Chinese breast cancer patients impairs its activity and is associated with increased breast cancer risk. Oncogene 2015 ; 34 : 5198-205.

100. Savitsky K, Bar-Shira A, Gilad S, et al. A single ataxia telangiectasia gene with a product similar to PI-3 kinase. Science 1995 ; 268: 1749-53.

101. Cavaciuti $\varepsilon$, Lauge A, Janin N, et al. Cancer risk according to type and location of ATM mutation in ataxia-telangiectasia families. Genes Chromosomes Cancer $2005 ; 42: 1-9$.

102. Thompson D, Duedal S, Kirner J, et al. Cancer risks and mortality in heterozygous ATM mutation carriers. J Natl Cancer Inst 2005 ; 97 : 813-22.

103. Olsen JH, Hahnemann JM, Borresen-Dale AL, et al. Breast and other cancers in 1445 blood relatives of 75 Nordic patients with ataxia telangiectasia. $\mathrm{Br}$ Cancer $2005 ; 93: 260-5$.

104. d'Almeida AK, Cavaciuti $\varepsilon$, Dondon MG, et al. Increased risk of breast cance among female relatives of patients with ataxia-telangiectasia: a causal relationship? Br J Cancer $2005 ; 93: 730-2$

105. Renwick A, Thompson D, Seal S, et al. ATM mutations that cause ataxiatelangiectasia are breast cancer susceptibility alleles. Nat Genet 2006 ; 38 : $873-5$

106. Balleine RL, Murali R, Bilous AM, et al. Histopathological features of breast cancer in carriers of ATM gene variants. Histopathology $2006 ; 49: 523-32$.

107. Tavtigian SV, Oefner PJ, Babikyan D, et al. Rare, evolutionarily unlikely missense substitutions in ATM confer increased risk of breast cancer. Am J Hum Genet $2009 ; 85:$ 427-46.

108. Goldgar DE, Healey S, Dowty JG, et al. Rare variants in the ATM gene and risk of breast cancer. Breast Cancer Res 2011; 13: R73. 


\section{RÉFÉRENCES}

109. Chenevix-Trench G, Spurdle AB, Gatei M, et al. Dominant negative ATM mutations in breast cance families.J Natl Cancer Inst $2002 ; 94: 205-15$.

110. Stankovic T, Kidd AM, Sutcliffe A, et al. ATM mutations and phenotypes in ataxia-telangiectasia families in the British Isles: expression of mutant ATM and the risk of leukemia, lymphoma, and breast cancer. Am J Hum Genet 1998 ; 62 : 334-45.

111. Roberts NJ, Jiao Y, Yu J, et al. ATM mutations in patients with hereditary pancreatic cancer. Cance Discov 2012; 2 : 41-6.

112. Helgason $\mathrm{H}$, Rafnar T, Olafsdottir HS, et al. Loss-of-function variants in ATM confer risk of gastric cancer. Nat Genet $2015 ; 47: 906-10$.

113. Kurian AW, Hare $\varepsilon \varepsilon$, Mills MA, et al. Clinical evaluation of a multiple-gene sequencing panel for hereditary cancer risk assessment. J Clin Oncol 2014 ; 32 : 2001-9.

114. De Nicolo A, Tancredi M, Lombardi G, et al. A novel breast cancer-associated BRIPI (FANCJ/ $\mathrm{BACH}$ ) germ-line mutation impairs protein stability and function. Clin Cancer Res $2008 ; 14$ 4672-80.

115. Eisinger F, Bressac B, Castaigne D, et al. Identification and management of hereditary predisposition to cancer of the breast and the ovary (update 2004). Bull Cancer $2004 ; 91: 219$ 37.

116. Szabo C, Masiello A, Ryan JF, Brody LC. The breast cancer information core: database design, structure, and scope. Hum Mutat $2000 ; 16: 123-31$

117. Beroud C, Letovsky SI, Braastad CD, et al. BRCA Share: a collection of clinical BRCA gene variants. Hum Mutat $2016 ; 37: 1318-28$.
118. King MC, Marks JH, Mandell JB, New York Breast Cancer Study G. Breast and ovarian cancer risks due to inherited mutations in BRCAl and BRCA2. Science $2003 ; 302: 643-6$.

119. Muller D, Bonaiti-Pellie C, Abecassis J, et al. BRCAl testing in breast and/ or ovarian cancer families from northeastern France identifies two common mutations with a founder effect. Fam Cancer 2004 ; 3 : 15-20.

120. Plon SE, Eccles DM, Easton D, et al. Sequence variant classification and reporting: recommendations for improving the interpretation of cancer susceptibility genetic test results. Hum Mutat $2008 ; 29$ : 1282-91.

121. Spurdle AB, Healey S, Devereau A, et al. ENIGMA: evidence-based network for the interpretation of germline mutant alleles: an international initiative to evaluate risk and clinical significance associated with sequence variation in BRCAl and BRCA2 genes. Hum Mutat $2012 ; 33: 2-7$.

122. Rebbeck TR, Friebel TM, Friedman $\varepsilon$, et al. Mutational spectrum in a worldwide study of 29,700 families with BRCAl or BRCA2 mutations. Hum Mutat $2018 ; 39: 593-620$.

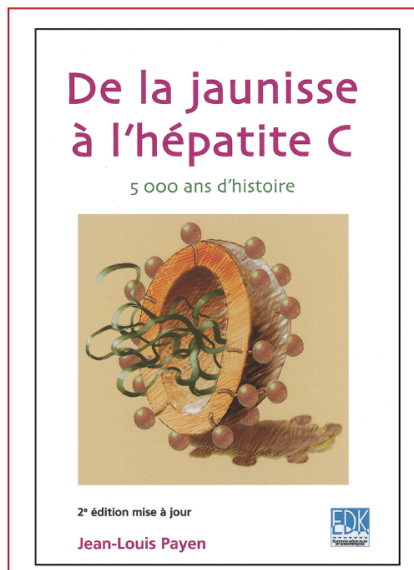

ISBN : 978-2-8425-4136-1 128 pages
L a jaunisse est un symptôme facilement identifiable; il paraissait bien naturel que l'homme, confronté à une modification de la couleur de ses yeux et de sa peau ait de tous temps recherché les causes de cette transformation.

II n'est donc pas surprenant que le premier traité de médecine, écrit 3000 ans avant J.C. par un médecin sumérien, décrive déjà la jaunisse. À chaque époque de l'histoire de la médecine, les praticiens, influencés par les concepts médicaux de leur temps, attribuèrent une ou plusieurs explications particulières à ce symptôme. Ainsi, du démon Ahhâzu des Sumériens à la sophistication des biotechnologies qui permirent la découverte du virus de I'hépatite C, le lecteur cheminera sur une période de 5000 ans au travers des différents continents.

Ici encore, l'histoire se révèle une formidable source de réflexion : le foie souvent impliqué dans l'apparition des jaunisses est-il le siège de l'âme?

Les expérimentations humaines chez des volontaires ou chez des enfants handicapés mentaux étaient-elles justifiées pour permettre la découverte des virus des hépatites?

Le formidable développement de la transfusion sanguine, des vaccinations, mais aussi de la toxicomanie explique-t-il les épidémies d'hépatites du xx siècle?

Autant de questions qui sont abordées dans ce livre passionnant et accessible à tous.

\section{À retourner à EDP Sciences, 17 avenue du Hoggar, 91944 Les Ulis Cedex}

Uél. : 0149856069 - Fax : 0149850345 - E-mail : francois.flori@edpsciences.org

NOM Prénom :

Adresse :

Code postal :

Ville :

Pays

Fonction :

Je souhaite recevoir l'ouvrage De la jaunisse à l'hépatite $\mathbf{C}, \mathbf{5} 000$ ans d'histoire : $12 €+3 €$ de port $=\mathbf{1 5} € \mathbf{T T C}$

en ................. exemplaire, soit un total de

$\ldots$

$\square$ Par chèque, à l'ordre de EDP Sciences

$\square$ Par carte bancaire : $\square$ Visa $\square$ Eurocard/Mastercard

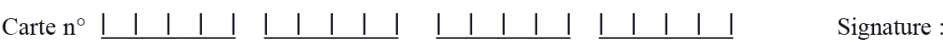

Date d'expiration

11111

$\mathrm{N}^{\circ}$ de contrôle au dos de la carte
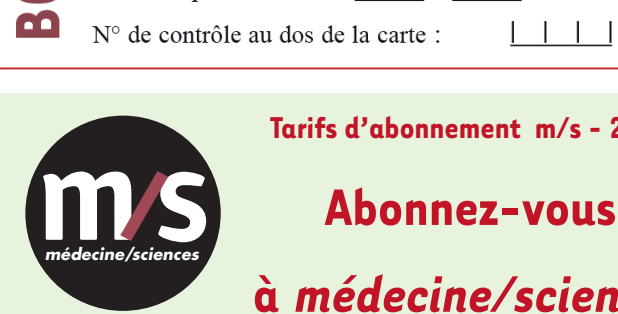

Tarifs d'abonnement m/s - 2019

$>$ Grâce à $m / s$, vivez en direct les progrès des sciences biologiques et médicales

Abonnez-vous

à médecine/sciences page 190 dans ce numéro de $\mathrm{m} / \mathrm{s}$

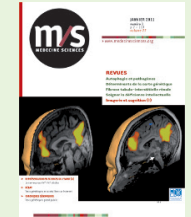

